\title{
Moment redistribution versus neutral axis depth in continuous PSC beams with external CFRP tendons
}

\author{
Tiejiong Lou ${ }^{1,2}$, Chengming Peng ${ }^{1}$, Theodore L. Karavasilis ${ }^{3}$, Di Min ${ }^{1}$, Wei Sun ${ }^{* 2}$ \\ 1. Hubei Key Laboratory of Roadway Bridge \& Structure Engineering, Wuhan University of \\ Technology, 430070 Wuhan, China \\ 2. Faculty of Engineering and Physical Sciences, University of Southampton, SO17 1BJ Southampton, \\ United Kingdom \\ 3. Department of Civil Engineering, University of Patras, GR-26500 Patras, Greece
}

\begin{abstract}
The neutral axis depth is adopted by many codes of practice as an indicator of flexural ductility to quantify moment redistribution in continuous prestressed concrete (PSC) beams. Moment redistribution, however, does not only depend on ductility but also on differences in stiffness along the length of the beam. Therefore, the effectiveness of using solely the neutral axis depth for redistribution quantification needs to be further evaluated. This study examines moment redistribution against neutral axis depth in two-span PSC beams with external CFRP tendons by applying a validated finite element model. The main variable is the content of non-prestressed reinforcement either at the positive or negative moment zone to generate varying stiffness differences between critical sections. The study shows that the use of neutral axis depth as a key parameter is inadequate when quantifying moment redistribution in these beams. Modifications of CSA, BSI and EC2 equations are proposed by introducing a parameter reflecting the impact of stiffness difference. The proposed equations show much better fit to the actual redistribution than that provided by equations in current design codes.
\end{abstract}

Keywords: Moment redistribution; Neutral axis depth; Carbon fibres; Prestressing

\footnotetext{
${ }^{*}$ Corresponding author.

E-mail address: Wei.Sun@soton.ac.uk (W. Sun).
} 


\section{Introduction}

Because of the advantages of excellent corrosive resistance, non-magnetic property and high strength-to-weight ratio, fibre reinforced polymer (FRP) is increasingly used in the field of civil engineering [1]. Numerous works on FRP reinforced/strengthened structures have been reported in recent years [2-6]. Of different composite materials, carbon FRP (CFRP) is most resistant to creep rupture (i.e. sustaining about $80 \%$ of the ultimate strength) $[7,8]$ and, therefore, this material appears to be the best choice for prestressing applications [9-11]. In external prestressing systems, the tendons are usually subject to harsh environment, thereby resulting in corrosive issue for conventional prestressing steel. Replacement of steel tendons by CFRP composites is an effective way to overcome the corrosive problem [12]. The use of CFRP tendons as a replacement of steel alternatives on the behaviour of prestressed concrete (PSC) beams with external tendons has been experimentally and numerically investigated [13-16]. The studies showed that CFRP tendons lead to similar structural behaviour of both simply supported $[13,14]$ and continuous beams $[15,16]$ in comparison with steel tendons.

In statically indeterminate members such as continuous beams, redistribution of bending moments occurs once the members exhibit nonlinear behaviour. Moment redistribution is associated to flexural ductility. As FRP composites are brittle material, the ability of FRP reinforced or strengthened concrete beams to redistribute moments is often limited [17-19]. Such limitation can be effectively overcome by providing longitudinal non-prestressed steel in PSC beams with external FRP tendons [20,21]. 
The effect of prestress level (15\%-75\% of the tensile failure strength of FRP tendons) and load pattern (symmetrical and unsymmetrical loads) on global redistribution behaviour of these beams was revealed [20]. More factors influencing moment redistribution in continuous PSC beams with external CFRP tendons were also examined [21]. Of various parameters investigated, the difference between the non-prestressed steel areas at the critical sections was found to be the most critical [21]. However, the impact of this parameter on the global redistribution during loading has not been analysed.

The current design codes suggest an elastic analysis with limited redistribution for exploiting the ductile capacity of continuous members. The neutral axis depth is a key parameter reflecting the flexural ductility [22] and this parameter is used by many codes of practice (e.g. CSA [23], BSI [24] and EC2 [25]) to quantify the permissible moment redistribution. However, moment redistribution is not only associated to the ductility but, more importantly, to the stiffness difference between the critical positive and negative moment sections $[21,26]$. Therefore, the use of neutral axis depth for the quantification of moment redistribution needs to be further evaluated. Although a few studies on continuous PSC beams with external FRP tendons have been carried out $[15,16,20,21]$, the redistribution behaviour of these beams has not been fully understood. For example, while the importance of stiffness difference is recognised $[21,26]$, its influence on the global redistribution and neutral axis behaviour of continuous PSC beams with external FRP tendons has never been addressed. Although code equations using neutral axis depth for redistribution quantification are 
available [23-25], these equations may not be reasonable because of the neglect of stiffness difference impact. An improvement of these equations is of practical importance. An in-depth study addressing these important issues is therefore essential.

In this study, moment redistribution against neutral axis depth in two-span PSC beams with external CFRP tendons is examined by using a validated numerical model. The main investigated variable is the content of non-prestressed reinforcement at either the positive or negative moment zone. This variable is selected so as to produce varying stiffness differences between the mid-span and inner support. Typical results in relation to global redistribution and neutral axis behaviour are presented. Several codes of practice that use the neutral axis depth for redistribution quantification are assessed. Reasonable modifications of these code equations are proposed by introducing a parameter describing the impact of stiffness difference.

\section{Numerical procedure}

\subsection{Material laws}

The model recommended in EC2 [25] is used to simulate the compressive behaviour of concrete. The stress $\left(\sigma_{c}\right)$ versus strain $\left(\varepsilon_{c}\right)$ relationship is expressed as follows:

$$
\frac{\sigma_{c}}{f_{c m}}=\frac{k\left(\varepsilon_{c} / \varepsilon_{c 0}\right)-\left(\varepsilon_{c} / \varepsilon_{c 0}\right)^{2}}{1+(k-2)\left(\varepsilon_{c} / \varepsilon_{c 0}\right)}
$$

where $f_{c m}=f_{c k}+8 ; f_{c k}$ is the cylinder compressive strength (MPa); $k=1.05 E_{c} \varepsilon_{c 0} / f_{c m} ; \varepsilon_{c 0}(\% 0)=0.7 f_{c m}^{0.31}<2.8 ; E_{c}$ is the modulus of elasticity (GPa). An elastic and linearly tension-stiffening law, as illustrated in [27], is used to simulate 
the tensile behaviour of concrete.

CFRP tendons are linear-elastic material, i.e.

$$
\sigma_{f}=E_{f} \varepsilon_{f} \leq f_{f}
$$

where $\sigma_{f}$ and $\varepsilon_{f}$ are stress and strain for CFRP composites, respectively; $E_{f}$ is the CFRP modulus of elasticity; $f_{f}$ is the ultimate strength.

The non-prestressed steel is linearly elastic until yielding, followed by perfectly plastic behaviour. The stress $\left(\sigma_{s}\right)$ versus strain $\left(\varepsilon_{s}\right)$ relationship is expressed by

$$
\begin{gathered}
\text { Prior to yielding, } \sigma_{s}=E_{s} \varepsilon_{s} \\
\text { After yielding, } \sigma_{s}=f_{y}
\end{gathered}
$$

where $E_{s}$ is the steel modulus of elasticity; $f_{y}$ is the yield strength.

\subsection{Beam element}

Consider a beam element with six degrees of freedom (see Fig. 1). Assuming that sections remain plane during the loading process as well as ignoring shear deformation, the axial strain is defined by:

$$
\varepsilon=\frac{\partial u}{\partial x}+\frac{1}{2}\left(\frac{\partial v}{\partial x}\right)^{2}-y \frac{\partial^{2} v}{\partial x^{2}}
$$

where $u$ is the axial displacement; and $v$ is the transverse displacement. Assume these displacements are linear and cubic polynomial functions, respectively. The relationship between element nodal loads $\left(\boldsymbol{P}^{e}\right)$ and displacements $\left(\boldsymbol{u}^{e}\right)$ is expressed by [27]

$$
\begin{gathered}
d \mathbf{P}^{e}=\left(\boldsymbol{K}_{o}^{e}+\boldsymbol{K}_{g}^{e}\right) d \boldsymbol{u}^{e} \\
\boldsymbol{K}_{o}^{e}=\int_{l} \boldsymbol{B}^{T} \boldsymbol{D}_{t} \boldsymbol{B} d x ; \quad \boldsymbol{K}_{g}^{e}=\int_{l} N \boldsymbol{J}^{T} \boldsymbol{J} d x
\end{gathered}
$$




$$
\begin{aligned}
& \boldsymbol{B}=\left[\begin{array}{cccccc}
-\frac{1}{l} & 0 & 0 & \frac{1}{l} & 0 & 0 \\
0 & \frac{6}{l^{2}}-\frac{12 p}{l^{2}} & \frac{4}{l}-\frac{6 p}{l} & 0 & -\frac{6}{l^{2}}+\frac{12 p}{l^{2}} & \frac{2}{l}-\frac{6 p}{l}
\end{array}\right]
\end{aligned}
$$

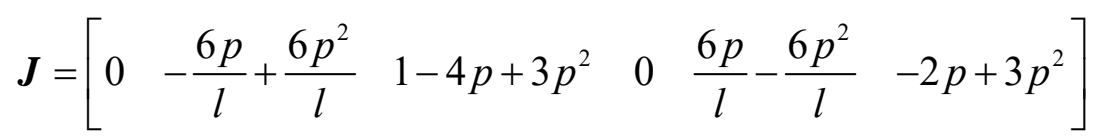

$$
\begin{aligned}
& \boldsymbol{D}_{t}=\left[\begin{array}{cc}
\sum_{i} E_{t i} A_{i} & \sum_{i} E_{t i} A_{i} y_{i} \\
\sum_{i} E_{t i} A_{i} y_{i} & \sum_{i} E_{t i} A_{i} y_{i}^{2}
\end{array}\right]
\end{aligned}
$$

where $N=\sum_{i} \sigma_{i} A_{i} ; p=x / l ; l$ is the element length; $\sigma$ represents the stress; $A$ represents the area; $E_{t}$ represents the tangential modulus. The summations are used for describing the entire cross section consisting of divided layers represented by the subscript $i$. External prestressing contributes to the beam element by equivalent loads. Detailed formulation on the beam element and the treatment of external tendons can be found elsewhere [27].

\subsection{Model validation}

Two continuous externally PSC beam specimens, designated as A-1 and B5, are selected for the investigation. Specimen A-1 was tested by Aravinthan et al. [28] and Specimen B5 by Du and Zhao [29]. Both specimens were of rectangular sections $(400 \times 150 \mathrm{~mm}$ for A-1 and $200 \times 300 \mathrm{~mm}$ for B5), continuous over two identical spans each of which was subjected to either two-point (A-1) or one-point (B5) loading. Specimen A-1 was post-tensioned with one external steel tendon with sectional area of $69.7 \mathrm{~mm}^{2}$, elastic modulus of $196 \mathrm{GPa}$, yield stress of $1464 \mathrm{MPa}$ and initial prestress of $362 \mathrm{MPa}$. Specimen B5 was post-tensioned with two external steel tendons with sectional area of $280 \mathrm{~mm}^{2}$, elastic modulus of $197 \mathrm{GPa}$, yield stress of 
$1420 \mathrm{MPa}$ and initial prestress of $1071 \mathrm{MPa}$. More details of the specimens can be referred to $[28,29]$. In analysing the specimens, the stress-strain relationship for steel tendons proposed in [30] is adopted.

Fig. 2 shows the predicted and experimental results regarding the load versus reaction, deflection and increase in tendon stress curves for Specimen A-1, and Fig. 3 shows the predicted and experimental load-moment curves for Specimen B5. The results by nonlinear analysis correspond well with the experimental data over both the elastic and inelastic ranges of loading. The load-reaction and load-moment curves by elastic analysis deviate from the experimental data in the inelastic range of loading due to moment redistribution. It is noted that the deviation between the elastic analysis and experiment is apparent for Specimen A-1, which had obvious stiffness difference between the critical positive and negative moment sections. On the other hand, such deviation is not so apparent for Specimen B5, which had identical stiffness at the mid-span and inner support. This indicates that the stiffness difference between the critical sections plays an important role in moment redistribution in the beams. In the following sections, the impact of stiffness difference on moment redistribution against neutral axis depth in continuous PSC beams with external CFRP tendons is explored comprehensively.

\section{Numerical investigation}

The structure and section of the reference beam are illustrated in Fig. 4. The PSC beam with external CFRP tendons has two identical spans with a total length of 20000 
$\mathrm{mm}$. The reinforcement arrangement is as follows: $\rho_{p}=0.34 \%, \rho_{s 1}=\rho_{s 2}=1.41 \%, \rho_{s 3}$ $=0.27 \%$, where $\rho_{p}=A_{p} /\left(b d_{p}\right), \rho_{s}=A_{s} /\left(b d_{p}\right)$. The subscripts $p, s 1, s 2$ and $s 3$ represent the tendon, non-prestressed tension steel at the mid-span and inner support and the non-prestressed compression steel, respectively; $b$ denotes the cross-sectional width; $d_{p}$ denotes the maximum effective tendon depth. The material properties are as follows: $f_{c k}=60 \mathrm{MPa} ; f_{f}=1840 \mathrm{MPa}, E_{f}=147 \mathrm{GPa}, f_{y}=450 \mathrm{MPa}, E_{s}=200 \mathrm{GPa}$. The initial prestress, $\sigma_{p 0}$, is $1104 \mathrm{MPa}$.

The main investigated variable is $\rho_{s 1}$ or $\rho_{s 2}$ so as to produce varying stiffness differences between the mid-span and inner support. In this section, the results for varied $\rho_{s 1}(0.27 \%-4.03 \%)$ and fixed $\rho_{s 2}(1.41 \%)$ are presented and discussed.

\subsection{Failure and crack mode}

Prior to failure that is caused by concrete crushing, the following phases are experienced sequentially in the beams with $\rho_{s 1}$ equal to or less than $1.03 \%$ : cracks occurring at the inner support and then at the mid-span, yielding of non-prestressed tension steel at the mid-span and then at the inner support. For $\rho_{s 1}$ equal to or greater than $1.41 \%$, the order of yielding at the critical sections is reversed, namely, yielding occurs firstly at the inner support, followed by yielding at the mid-span.

Fig. 5 shows the strain distribution at ultimate at the bottom and top fibres of the beams with different $\rho_{s 1}$ values. The beam concrete is crushed when the specified ultimate compressive strain of 0.003 is reached at the mid-span. Meanwhile, the compressive strain at the inner support may be far below (for $\rho_{s 1}=0.27 \%$ ), below (for $\rho_{s 1}=1.41 \%$ ) or very close to its ultimate capacity (for $\rho_{s 1}=4.03 \%$ ). In addition, when 
$\rho_{s 1}=0.27 \%$, there occurs a large tensile strain at the mid-span against slight strains over other positive moment regions, indicating strain or crack concentration. As $\rho_{s 1}$ increases, the crack width at the mid-span is significantly reduced and the crack zone over the positive moment region is extended. On the other hand, increasing $\rho_{s 1}$ leads to increased crack width at the inner support and reduced crack zone over the negative moment region.

\subsection{Deformation behaviour}

Fig. 6 shows that the beams with different $\rho_{s 1}$ values exhibit the same load-deflection responses until cracking. Thereafter, a higher $\rho_{s 1}$ leads to stiffer structural behaviour, attributed to the higher cross-sectional stiffness over the positive moment region. The beam with $\rho_{s 1}$ of $0.27 \%$ exhibits the smallest deformation capacity. This can be explained by the fact the inner support section is well below its strength capacity when the concrete at the mid-span is crushed. As $\rho_{s 1}$ increases up to $1.41 \%$, the exploitation of the inner support section is improved and, therefore, the deformation capacity is increased. The change in deformation capacity with varying $\rho_{s 1}$ appears to be not apparent when $\rho_{s 1}$ is greater than $1.41 \%$. This is caused by the combined effect of the exploitation of the inner support section and the change of flexural ductility of the mid-span section.

Fig. 7 shows the deflection development against the stress increase in external tendons for different $\rho_{s 1}$ values. There is nearly linear relationship between the tendon stress increase and the deflection. For a given tendon stress, a higher $\rho_{s 1}$ leads to a higher deflection. Since the stress in external tendons is evenly distributed over the 
full length, external tendons are well below their tensile capacity at failure.

\subsection{Neutral axis evolution with the moment}

The neutral axis depth $c$ is recognised to have critically important relationship with moment redistribution. This is reflected in various design codes such as CSA [23], BSI [24] and EC2 [25]. A good understanding of the neutral axis evolution during the loading process is therefore essential. For the investigated beams under self-weight and external prestressing, there is a slight hogging curvature at the mid-span and a slight sagging curvature at the inner support. Accordingly, the initial value of $c$ is negative, namely, the neutral axis situates above (below) the top (bottom) of the mid-span (inner support). The initial curvature gradually vanishes after loading. Then, the sagging (hogging) curvature at the mid-span (inner support) appears and increases. Accordingly, the value of $c$ is quickly reduced to the negative infinity, and then suddenly changed to the positive infinity and rapidly reduced thereafter.

The evolution of $c$ (for $c \leq 600 \mathrm{~mm}$ ) with the bending moment $M$ for different $\rho_{s 1}$ values is presented in Fig. 8. The $M-c$ curve is characterised by four stages. The first stage is featured by a dramatic decrease in $c$ until the cracking moment is reached. The second stage is initiated by the appearance of flexural cracks and ended by the stabilisation of the crack development. This stage shows a reduced decrease rate of $c$ with increasing moment. The decrease rate is significantly further reduced in the third stage until the yielding of non-prestressed tension steel. This is followed by the fourth stage, which shows a resume of a quick decrease of $c$ until failure. At the mid-span, the $M-c$ curves for different $\rho_{s 1}$ values differ after cracking, i.e. a higher $\rho_{s 1}$ value 
leads to a slower decrease in $c$. For the inner support, the $M-c$ curves for different $\rho_{s 1}$ values are almost identical. In other words, the neutral axis evolution at the inner support is independent of the reinforcement content at the mid-span. This observation confirms that the neutral axis depth is only a section-related parameter, rather than a structure-related parameter. Therefore, it is not adequate to use this parameter to quantify the moment redistribution, which mainly results from the structural redundancy.

\subsection{Load-reaction relationship}

Fig. 9 shows the load-reaction curves for different $\rho_{s 1}$ values. Both the actual reactions generated by a nonlinear analysis and the elastic reactions generated by an elastic analysis are demonstrated. The reaction comprises the load-induced reaction and prestressing-induced reaction (secondary reaction). The secondary reaction for the investigated beams is positive at the outer support and negative at the inner support. Therefore, if the tendons are linearly transformed to be concordant to eliminate the secondary reaction, the outer support reaction would be smaller and the inner support reaction would be bigger.

According to the linear-elastic theory, the support reaction develops linearly throughout the loading process. Prior to cracking, the actual reaction development is identical to the elastic one. On cracking, the actual reaction begins to deviate from the elastic one due to redistribution of moments. The deviation varies significantly according to the $\rho_{s 1}$ value. For $\rho_{s 1}=0.27 \%$, the cracking induced reduction in flexural stiffness at the mid-span is significantly more pronounced than that at the inner 
support, leading to redistribution of moments from the mid-span to the inner support. Consequently, the actual reaction at the outer support tends to be smaller than the elastic one while the actual reaction at the inner support tends to be larger than the elastic one. The deviation tends to be increasingly apparent as the load increases. As $\rho_{s 1}$ gradually increases, the difference between the actual and elastic reactions diminishes, indicating reduced moment redistribution. When $\rho_{s 1}$ is equal to $1.03 \%$, the difference is negligible over the inelastic loading range, indicating that moment redistribution is negligible. When $\rho_{s 1}$ increases to $1.41 \%$, the actual reaction at the outer (inner) support after cracking turns to be slightly larger (smaller) than the elastic one. This indicates that bending moments are redistributed slightly from inner support towards mid-span. The deviation of the actual reaction from the elastic reaction is more and more apparent with the continuing increase of $\rho_{s 1}$. When $\rho_{s 1}$ is equal to $4.03 \%$, the actual reaction at the outer (inner) support after cracking is significantly larger (smaller) than the elastic one, indicating significant redistribution of moments from inner support towards mid-span.

\subsection{Evolution of bending moments and moment ratio with the load}

Fig. 10 shows the evolution of bending moments and moment ratio for different $\rho_{s 1}$ values. In Fig. 10, $M_{1}$ and $M_{2}$ refer to the actual moments, induced by the applied load, at the mid-span and inner support, respectively; $\left(M_{1}\right)_{e l a}$ and $\left(M_{2}\right)_{\text {ela }}$ refer to elastic moments, induced by the applied load, at the mid-span and inner support, respectively. The elastic moment development shows a linear behaviour and, therefore, the elastic moment ratio remains constant over the loading process. Because 
of the influence of reinforcement content, the value of $\left(M_{1}\right)$ ela $/\left(M_{2}\right)_{\text {ela }}$ varies from 0.8 for $\rho_{s 1}=0.27 \%$ to 0.91 for $\rho_{s 1}=4.03 \%$.

Similar to the behaviour of reaction development, the actual moment development differs from the elastic one after the cracking load is reached. Correspondingly, the actual moment ratio is no longer a constant. The actual moment ratio is associated to moment redistribution: an increase in $M_{1} / M_{2}$ represents redistribution of moments from inner support towards mid-span; a decrease in $M_{1} / M_{2}$ indicates moment redistribution from mid-span towards inner support; a stabilisation of $M_{1} / M_{2}$ implies stabilising moment redistribution; the larger the deviation between the actual moment ratio and elastic one, the higher the amount of moment redistribution. The evolution of the actual moment ratio strongly depends on $\rho_{s 1}$, as can be seen in Fig. 10.

\subsection{Neutral axis evolution against moment redistribution}

The degree of redistribution is defined as:

$$
\beta=1-\frac{M}{M_{\text {ela }}}
$$

It should be noted that the actual moment $M$ and elastic moment $M$ ela are contributed by the live and dead loads as well as the secondary reaction induced by external prestressing.

Fig. 11 presents the evolution of $\beta$ against $c / d$ (for $c / d \leq 1$ ) for different $\rho_{s 1}$ values. The effective depth $d$ is calculated by

$$
d=\frac{A_{p} \sigma_{p 0} d_{p}+A_{s} f_{y} d_{s}}{A_{p} \sigma_{p 0}+A_{s} f_{y}}
$$

where $d_{p}$ and $d_{s}$ are the depths of prestressed and non-prestressed reinforcement, 
respectively. The redistribution is zero with the rapid decrease in $c / d$ until cracking. Moment redistribution occurs afterwards, and the behaviour is affected typically by stabilising of crack evolution and yielding of non-prestressed tension steel at the critical sections. The beams having $\rho_{s 1}=0.27 \%$ and $0.65 \%$ show similar behaviour. Immediately after cracking, there occur slightly positive moment redistribution over inner support and negative one over mid-span. This is attributed to the occurrence of first crack at the inner support, leading to moment redistribution from inner support towards mid-span. Cracking also occurs at the mid-span very soon. When the crack evolution at both the critical sections stabilises, moments start to be redistributed from mid-span (weaker section) towards inner support (stronger section). Consequently, the positive (negative) redistribution at the inner support (mid-span) decreases (increases) quickly to a negative (positive) value, accompanying with a slower decrease in $c / d$. When first yielding occurs at the mid-span, further moments are redistributed from mid-span to inner support, resulting in a faster decrease (increase) of moment redistribution over inner support (mid-span). Meanwhile, the variation in $c / d$ is limited. Such behaviour continues until yielding at the inner support. Thereafter, the evolution of moment redistribution is insignificant with varying $c / d$. For $\rho_{s 1}=1.03 \%$, yielding at critical sections occurs almost simultaneously. Therefore, the decrease (increase) in positive (negative) redistribution over inner support (mid-span) after stabilising of crack evolution is not so important. For $\rho_{s 1}=1.41 \%$ or above, moment redistribution tends to slightly decrease, stabilise or slightly increase, after stabilising of crack evolution, until first yielding at the inner support. This is followed by a quick 
increase (decrease) in positive (negative) moment redistribution over inner support (mid-span) until second yielding at the mid-span, accompanying with limited variation in $c / d$. Afterwards, the variation of $\beta$ is negligible while the variation of $c / d$ is significant at the mid-span and not so significant at the inner support.

\section{Proposed equations based on the parameter $c / d$}

The parameter $c / d$ (at ultimate) is mostly adopted in current design codes around the world for calculating the moment redistribution in statically indeterminate structures. The results presented in the previous section shows that the parameter $c / d$ is only section-related while moment redistribution is remarkably affected by varying $\rho_{s 1}\left(\rho_{s 2}\right.$ is fixed) and consequently by the stiffness difference between the critical sections. In this section, typical codes of practice are assessed and possible modifications of the code equations are suggested to take the stiffness difference into consideration. Unless otherwise stated, the numerical results presented herein are generated for $f_{c k}=60 \mathrm{MPa}$. The flexural stiffness of an externally PSC section could be described by the combined reinforcement index $\omega$, which consists of the prestressed reinforcement index $\omega_{p}$ and non-prestressed reinforcement index $\omega_{s}$.

$$
\begin{gathered}
\omega=\omega_{p}+\omega_{s} \\
\omega_{p}=\frac{\rho_{p} \sigma_{p 0}}{f_{c k}}, \omega_{s}=\frac{\rho_{s} f_{y}}{f_{c k}}
\end{gathered}
$$

Three typical design codes are investigated herein, i.e. CSA [23], BSI [24] and EC2 [25]. The ACI code [31] is not evaluated in this study because this code does not adopt the parameter $c / d$ for quantifying moment redistribution (it uses the strain in 
extreme tensile steel instead).

A single parameter $c / d$ is used in CSA Eq. (14) and BSI Eq. (15) for redistribution quantification of continuous PSC beams.

$$
\begin{gathered}
\beta=0.3-0.5 c / d \\
\beta=0.5-c / d
\end{gathered}
$$

The maximum redistribution allowed by CSA and BSI is $20 \%$. The equation suggested by EC2 accounts for the effect of concrete grade and is expressed by

$$
\beta= \begin{cases}0.56-k_{1} c / d & \text { for } f_{c k} \leq 50 \mathrm{MPa} \\ 0.46-k_{1} c / d & \text { for } f_{c k}>50 \mathrm{MPa}\end{cases}
$$

where

$$
k_{1}=1.25\left(0.6+0.0014 / \varepsilon_{c u 2}\right)
$$

in which $\varepsilon_{c u 2}$ is the ultimate strain which is determined according to EC2 by

$$
\varepsilon_{c u 2}(\%)= \begin{cases}3.5 & \text { for } f_{c k} \leq 50 \mathrm{MPa} \\ 2.6+35\left[\left(90-f_{c k}\right) / 100\right]^{4} & \text { for } f_{c k}>50 \mathrm{MPa}\end{cases}
$$

The maximum redistribution allowed by EC2 is $30 \%$.

Fig. 12 illustrates the $\beta$-c/d relationship at ultimate obtained from the finite element analysis (FEA) along with the code curves (BSI, EC2 and CSA). The FEA data are generated by either varying $\omega_{1}$ ( $\omega_{2}$ is fixed) or $\omega_{2}$ ( $\omega_{1}$ is fixed) from 0.073 to 0.355 , where $\omega_{1}$ and $\omega_{2}$ are the combined reinforcement indexes at the mid-span and inner support, respectively. According to FEA, as $\omega_{2}$ varies from 0.073 to 0.355 , the value of $c / d$ at the mid-span is almost unchanged, accompanying with a significant change of $\beta$ at the mid-span from $-25.0 \%$ to $21.9 \%$. In the case that $\omega_{1}$ is a variable, the variation of $c / d$ at the inner support is very slight when $\beta$ at the inner support 
varies remarkably between $-35.5 \%$ and $42.8 \%$. The afore-mentioned observations are inconsistent with the design codes, i.e. there is significant change in $c / d$ with the $\beta$ value. Therefore, it can be concluded that the stiffness difference between the critical sections cannot be reflected in these codes.

To further confirm this statement, the $\beta-\ln \left(\omega_{1} / \omega_{2}\right)$ relationship by FEA is compared to the code predictions in Fig. 13. The results for the mid-span section shown in Fig. 13(a) are produced by varying $\omega_{2}\left(\omega_{1}\right.$ is fixed), while those for the inner support section shown in Fig. 13(b) are produced by varying $\omega_{1}\left(\omega_{2}\right.$ is fixed). The code predictions demonstrate nearly stabilising $\beta$ with varying $\ln \left(\omega_{1} / \omega_{2}\right)$. This is, however, contradicts with the FEA results, which show a remarkable change in $\beta$ with increasing $\ln \left(\omega_{1} / \omega_{2}\right)$. Therefore, the design codes neglect the structure-related parameter $\omega_{1} / \omega_{2}$ and, consequently, they cannot accurately predict the moment redistribution in continuous PSC beams.

In order to introduce the parameter $\omega_{1} / \omega_{2}$ which describes the stiffness difference between the critical sections, CSA Eq. (14), BSI Eq. (15) and EC2 Eq. (16) are modified by introducing coefficients $\lambda_{c s a}, \lambda_{b s i}$ and $\lambda_{e c 2}$, respectively. The modified equations are expressed as follows:

$$
\begin{gathered}
\beta=\lambda_{c s a}(0.3-0.5 c / d) \\
\beta=\lambda_{b s i}(0.5-c / d) \\
\beta= \begin{cases}\lambda_{e c 2}\left(0.56-k_{1} c / d\right) & \text { for } f_{c k} \leq 50 \mathrm{MPa} \\
\lambda_{e c 2}\left(0.46-k_{1} c / d\right) & \text { for } f_{c k}>50 \mathrm{MPa}\end{cases}
\end{gathered}
$$

where $\lambda_{c s a}, \lambda_{b s i}$ and $\lambda_{e c 2}$ are coefficients related to $\omega_{1} / \omega_{2}$. The code equations, in general, are applied to both sagging and hogging sections. However, the neutral axis 
evolution against moment redistribution for critical sagging and hogging sections of an externally PSC beam is quite different, as can be seen in Fig. 11. It is therefore necessary to obtain the values of $\lambda_{c s a}, \lambda_{b s i}$ and $\lambda_{e c 2}$ separately for the mid-span and inner support sections.

The variations of $\lambda_{c s a}$ and $\lambda_{b s i}$ against $\ln \left(\omega_{1} / \omega_{2}\right)$ for the mid-span section of the beams with varied $\omega_{2}$ and fixed $\omega_{1}$ are shown in Fig. 14(a) and (b), respectively, while the variations of $\lambda_{e c 2}$ for $f_{c k}=40$ (representing the case of $f_{c k} \leq 50 \mathrm{MPa}$ ) and 60 $\mathrm{MPa}$ (representing the case of $f_{c k}>50 \mathrm{MPa}$ ) are shown in Fig. 14(c) and (d), respectively. According to the fit curves, $\lambda_{c s a}, \lambda_{b s i}$ and $\lambda_{e c 2}$ for the mid-span section are expressed as follows:

$$
\begin{gathered}
\lambda_{c s a}=-0.18-1.46 \ln \left(\omega_{1} / \omega_{2}\right) \\
\lambda_{b s i}=-0.12-0.96 \ln \left(\omega_{1} / \omega_{2}\right) \\
\lambda_{e c 2}= \begin{cases}-0.13-0.98 \ln \left(\omega_{1} / \omega_{2}\right) & \text { for } f_{c k} \leq 50 \mathrm{MPa} \\
-0.18-1.46 \ln \left(\omega_{1} / \omega_{2}\right) & \text { for } f_{c k}>50 \mathrm{MPa}\end{cases}
\end{gathered}
$$

The $\lambda_{c s a}-\ln \left(\omega_{1} / \omega_{2}\right)$ and $\lambda_{b s i}-\ln \left(\omega_{1} / \omega_{2}\right)$ relationships for the inner support section of the beams with varied $\omega_{1}$ and fixed $\omega_{2}$ are shown in Fig. 15(a) and (b), respectively, while the $\lambda_{e c 2}-\ln \left(\omega_{1} / \omega_{2}\right)$ relationships for $f_{c k}=40$ and $60 \mathrm{MPa}$ are shown in Fig. 15(c) and (d), respectively. According to the fit curves, $\lambda_{c s a}, \lambda_{b s i}$ and $\lambda_{e c 2}$ for the inner support section are expressed as follows:

$$
\begin{gathered}
\lambda_{c s a}=0.43+2.71 \ln \left(\omega_{1} / \omega_{2}\right)-0.84 \ln ^{2}\left(\omega_{1} / \omega_{2}\right) \\
\lambda_{b s i}=0.29+1.87 \ln \left(\omega_{1} / \omega_{2}\right)-0.68 \ln ^{2}\left(\omega_{1} / \omega_{2}\right) \\
\lambda_{e c 2}=\left\{\begin{array}{l}
0.31+2.09 \ln \left(\omega_{1} / \omega_{2}\right)-0.94 \ln ^{2}\left(\omega_{1} / \omega_{2}\right) \\
0.58+2.45 \ln \left(\omega_{1} / \omega_{2}\right)-2.75 \ln ^{2}\left(\omega_{1} / \omega_{2}\right)+2.67 \ln ^{3}\left(\omega_{1} / \omega_{2}\right) \text { for } f_{c k}>50 \mathrm{MPa}
\end{array}\right.
\end{gathered}
$$


Correlations of simplified equations with the $\beta$ values obtained by FEA for the mid-span and inner support are demonstrated in Figs. 16 and 17, respectively. In Fig. 16, a total of 42 external CFRP tendon specimens with varying either $\omega_{1}$ or $\omega_{2}$ from 0.073 to 0.355 and $f_{c k}$ from 40 to $90 \mathrm{MPa}$ are used for the correlations. In Fig. 17, in addition to the afore-mentioned 42 specimens, another 49 external CFRP tendon specimens having various variables presented in [21] are also used for the correlations. Those included the areas of non-prestressed reinforcement and external tendons, CFRP elastic modulus, effective tendon depth, effective prestress, concrete strength, span length and load geometry. It is seen in Figs. 16 and 17 that the design codes (CSA, BSI and EC2) exhibit poor fit to the $\beta$ values by FEA. By including the parameter $\omega_{1} / \omega_{2}$, the proposed equations (i.e. modified CSA, BSI and EC2 equations) correlate very well with the FEA predictions for both the mid-span and inner support sections.

\section{Conclusions}

A numerical investigation is carried out to evaluate moment redistribution against neutral axis depth in two-span PSC beams with external CFRP tendons, emphasising on the impact of differences in stiffness between the mid-span and the inner support. The stiffness difference is generated by varying the content of non-prestressed reinforcement at either the positive or negative moment zone. It is shown that varying the stiffness difference leads to a remarkable change in behaviour related to moment 
redistribution, e.g. load-reaction relationship, evolution of moments and moment ratio, and development of moment redistribution. On the other hand, varying the stiffness at the mid-span does not influence the neutral axis evolution at the inner support, and vice versa. This confirms that the neutral axis depth is only a section-related parameter. Therefore, the use of this parameter for the quantification of moment redistribution, which is the case in various codes of practice, is not adequate.

Three typical code equations that use the neutral axis depth as a key parameter for redistribution quantification are investigated, namely CSA, BSI and EC2. The results show that these codes fail to consider the impact of stiffness difference and consequently cannot predict accurately the amount of moment redistribution. Reasonable modifications of CSA, BSI and EC2 equations are proposed to quantify the moment redistribution in continuous PSC beams with external CFRP tendons. Simplified equations for both mid-span and inner support sections are developed. By introducing the parameter $\omega_{1} / \omega_{2}$, which accounts for the impact of stiffness difference, the proposed equations show a much better fit to the redistribution values by FEA than that provided by equations in current design codes.

It should be noted that for conventional continuous reinforced concrete (RC) and PSC beams, the stiffness difference is also a critical factor influencing moment redistribution. Since both moment redistribution and neutral axis evolution highly depend on the structural typology, the modified CSA, BSI and EC2 equations proposed in this study, however, may not be applied to conventional RC and PSC beams and requires further validation. 


\section{Acknowledgements}

The work has been supported by the Fundamental Research Funds for the Central Universities under Grant No. 2018IVA006 and by the European Union's Horizon 2020 research and innovation programme under the Marie Sklodowska-Curie grant agreement No. 751921.

\section{References}

[1] Kim YJ. State of the practice of FRP composites in highway bridges. Engineering Structures 2019; 179: 1-8.

[2] De Maio U, Fabbrocino F, Greco F, Leonetti L, Lonetti P. A study of concrete cover separation failure in FRP-plated RC beams via an inter-element fracture approach. Composite Structures 2019; 212: 625-636.

[3] Feng B, Wang X, Wu Z. Fatigue life assessment of FRP cable for long-span cable-stayed bridge. Composite Structures 2019; 210: 159-166.

[4] Al-Lebban YF, Mackie KR. Polyurethane-FRP external strengthening of RC beams with no steel stirrups. ASCE Journal of Composites for Construction 2019; 23(1): 04018074.

[5] Chen C, Cheng L, Sui L, Xing F, Li D, Zhou Y. Design method of end anchored FRP strengthened concrete structures. Engineering Structures 2018; 176: 143-158.

[6] Jiang SF, Zeng X, Shen S, Xu C. Experimental studies on the seismic behavior of earthquake-damaged circular bridge columns repaired by using combination of 
near-surface-mounted BFRP bars with external BFRP sheets jacketing. Engineering Structures 2016; 106: 317-331.

[7] fib. Model Code 2010. Bulletins 55 and 56, International Federation for Structural Concrete. Lausanne, Switzerland; 2012.

[8] ACI committee 440. Prestressing concrete structures with FRP tendons. ACI 440.4R-04, Farmington Hills, MI; 2004.

[9] Hosseini A, Ghafoori E, Motavalli M, Nussbaumer A, Zhao XL, Al-Mahaidi R, Terrasi G. Development of prestressed unbonded and bonded CFRP strengthening solutions for tensile metallic members. Engineering Structures 2019; 181: $550-561$.

[10] Martinelli E, Hosseini A, Ghafoori E, Motavalli M. Behavior of prestressed CFRP plates bonded to steel substrate: Numerical modeling and experimental validation. Composite Structures 2019; 207: 974-984.

[11] Sovjak R, Havlasek P, Vitek J. Long-term behavior of concrete slabs prestressed with CFRP rebars subjected to four-point bending. Construction and Building Materials 2018; 188: 781-792.

[12] Grace NF, Abdel-Sayed G. Behavior of externally draped CFRP tendons in prestressed concrete bridges. PCI Journal 1998; 43(5): 88-101.

[13]Lou T, Lopes SMR, Lopes AV. Numerical analysis of behaviour of concrete beams with external FRP tendons. Construction and Building Materials 2012; 35 : 970-978.

[14]Bennitz A, Schmidt JW, Nilimaa J, Taljsten B, Goltermann P, Ravn DL. 
Reinforced concrete T-beams externally prestressed with unbonded carbon fiber-reinforced polymer tendons. ACI Structural Journal 2012; 109(4): 521-530.

[15] Tan KH, Tjandra RA. Strengthening of RC continuous beams by external prestressing. ASCE Journal of Structural Engineering 2007; 133(2): 195-204.

[16]Lou T, Lopes SMR, Lopes AV. Effect of linear transformation on nonlinear behavior of continuous prestressed beams with external FRP cables. Engineering Structures 2017; 147: 410-424.

[17] Tajaddini A, Ibell T, Darby A, Evernden M, Silva P. Prediction of capacity for moment redistribution in FRP-strengthened continuous RC T-beams. ASCE Journal of Composites for Construction 2017; 21(1): 0000719.

[18] Kara IF, Ashour AF. Moment redistribution in continuous FRP reinforced concrete beams. Construction and Building Materials 2013; 49: 939-948.

[19] Santos P, Laranja G, Franca PM, Correia JR. Ductility and moment redistribution capacity of multi-span T-section concrete beams reinforced with GFRP bars. Construction and Building Materials 2013; 49: 949-961.

[20]Lou T, Lopes SMR, Lopes AV. External CFRP tendon members: Secondary reactions and moment redistribution. Composites Part B: Engineering 2014; 57: $250-261$.

[21]Lou T, Lopes SMR, Lopes AV. Factors affecting moment redistribution at ultimate in continuous beams prestressed with external CFRP tendons. Composites Part B: Engineering 2014; 66: 136-146.

[22]Bernardo LFA, Lopes SMR. Neutral axis depth versus flexural ductility in 
high-strength concrete beams. ASCE Journal of Structural Engineering 2004; 130(3), 452-459.

[23]CSA. Design of concrete structures. A23.3-04, Canadian Standards Association, Mississauga, Ontario, Canada; 2004.

[24]BSI. Structural use of Concrete - Part 1: Code of practice for design and construction. BS8110, British Standards Institution, London, UK; 2007.

[25]CEN. Eurocode 2: Design of concrete structures - Part 1-1: General rules and rules for buildings. EN 1992-1-1, European Committee for Standardization, Brussels, Belgium; 2004.

[26] Oehlers DJ, Liu IST, Ju G, Seracino R. Moment redistribution in continuous plated RC flexural members. Part 2: Flexural rigidity approach. Engineering Structures 2004; 26: 2209-2218.

[27]Lou T, Xiang Y. Finite element modeling of concrete beams prestressed with external tendons. Engineering Structures 2006; 28(14): 1919-1926.

[28] Aravinthan T, Witchukreangkrai E, Mutsuyoshi H. Flexural behavior of two-span continuous prestressed concrete girders with highly eccentric external tendons. ACI Structural Journal 2005; 102(3): 402-411.

[29] Du J, Zhao Y. Experimental study of moment redistribution in externally prestressed concrete continuous beams. Engineering Mechanics 2013; 30(3): 263-269. (in Chinese)

[30] Menegotto M, and Pinto PE. Method of analysis for cyclically loaded reinforced concrete plane frames. IABSE preliminary report for symposium on resistance 
and ultimate deformability of structures acted on well-defined repeated loads, Lisbon; 1973. pp. 15-22.

[31]ACI Committee 318. Building code requirements for structural concrete (ACI 318-14) and commentary (ACI 318R-14). American Concrete Institute, Farmington Hills, MI; 2014. 


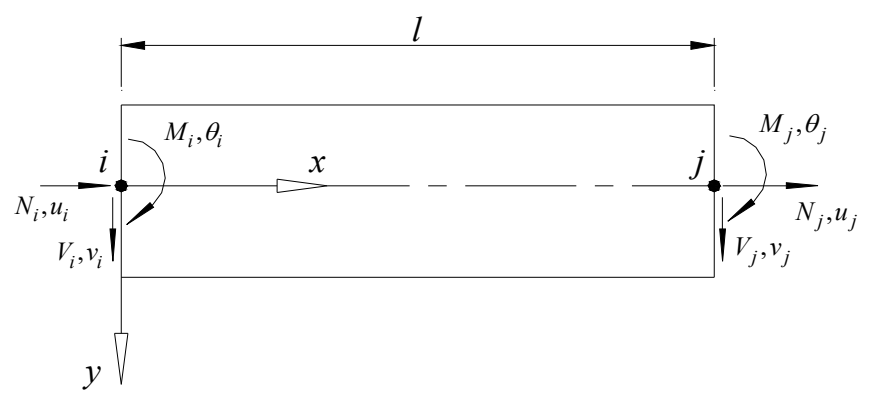

Fig. 1. Beam element. 

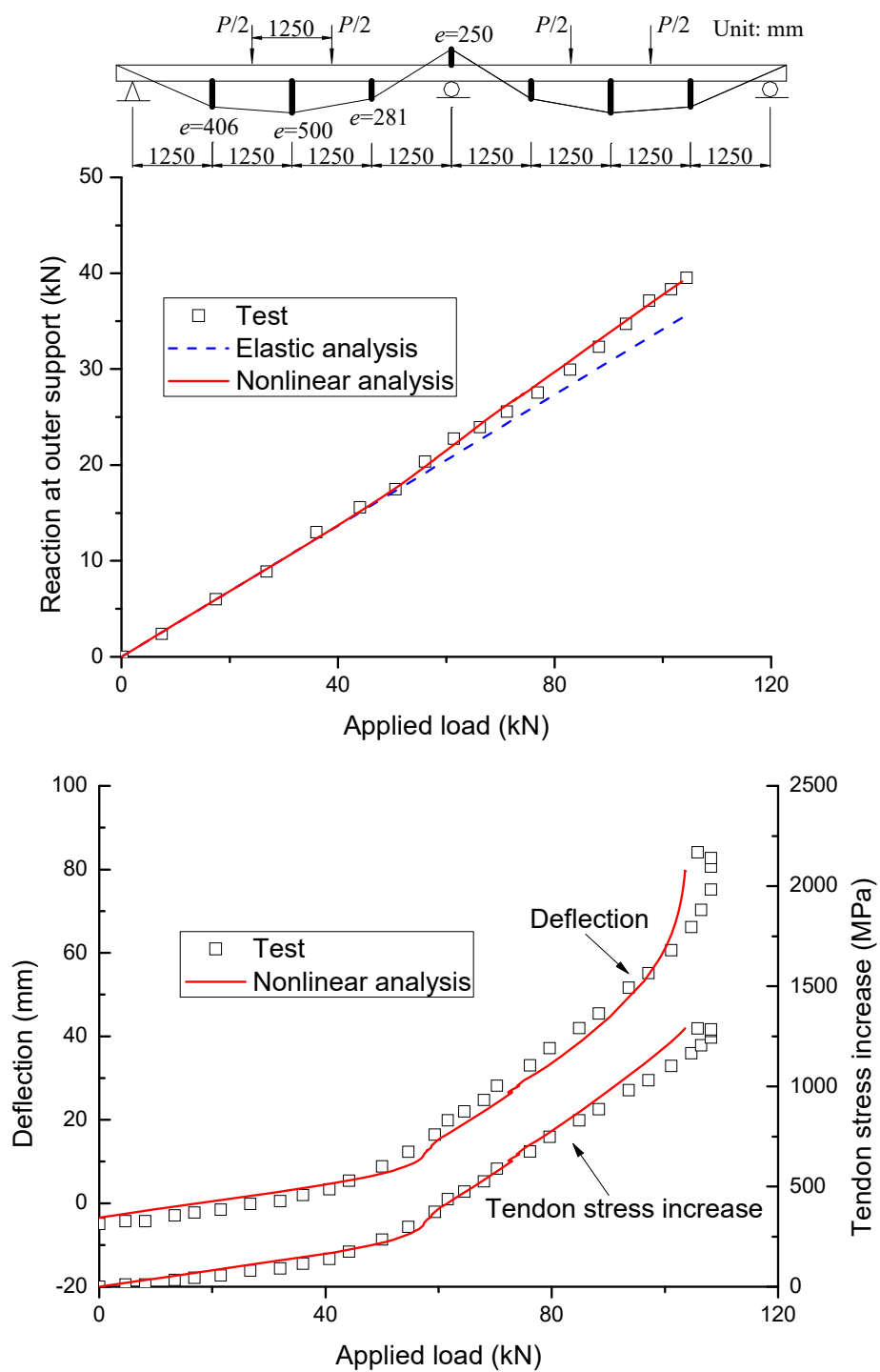

Fig. 2. Comparison with test results of Specimen A-1 [28]. 


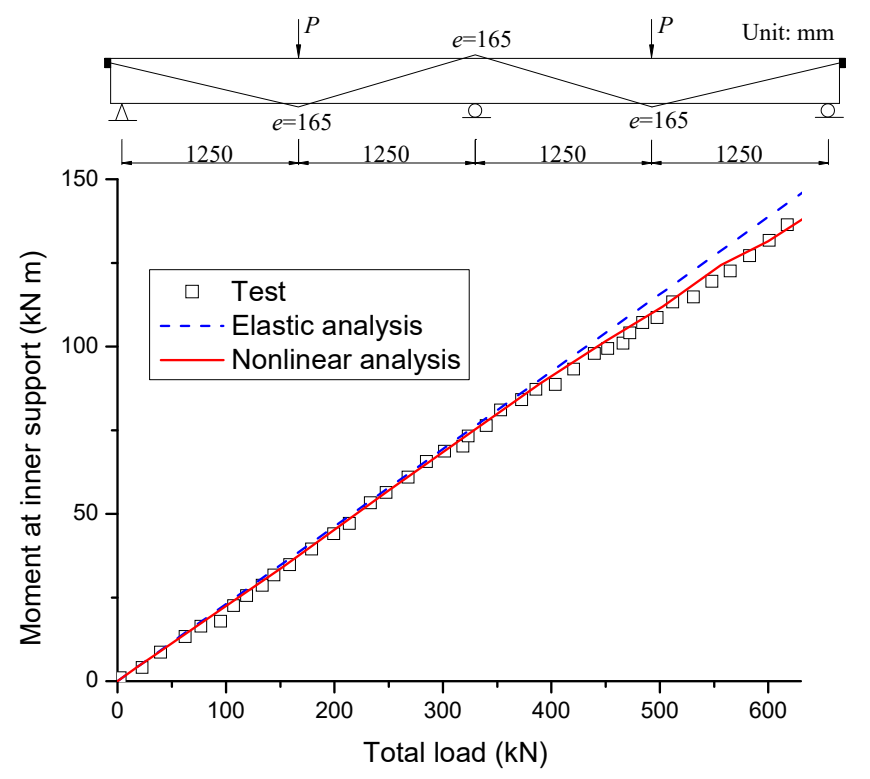

Fig. 3. Comparison with test results of Specimen B5 [29]. 

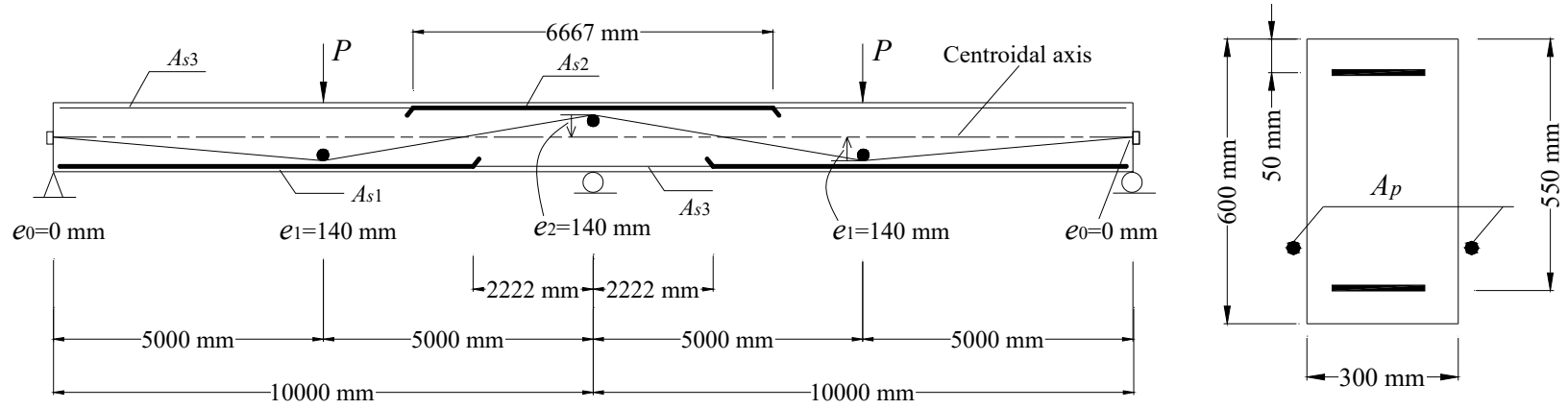

Fig. 4. Details of reference PSC beam with external CFRP tendons. 

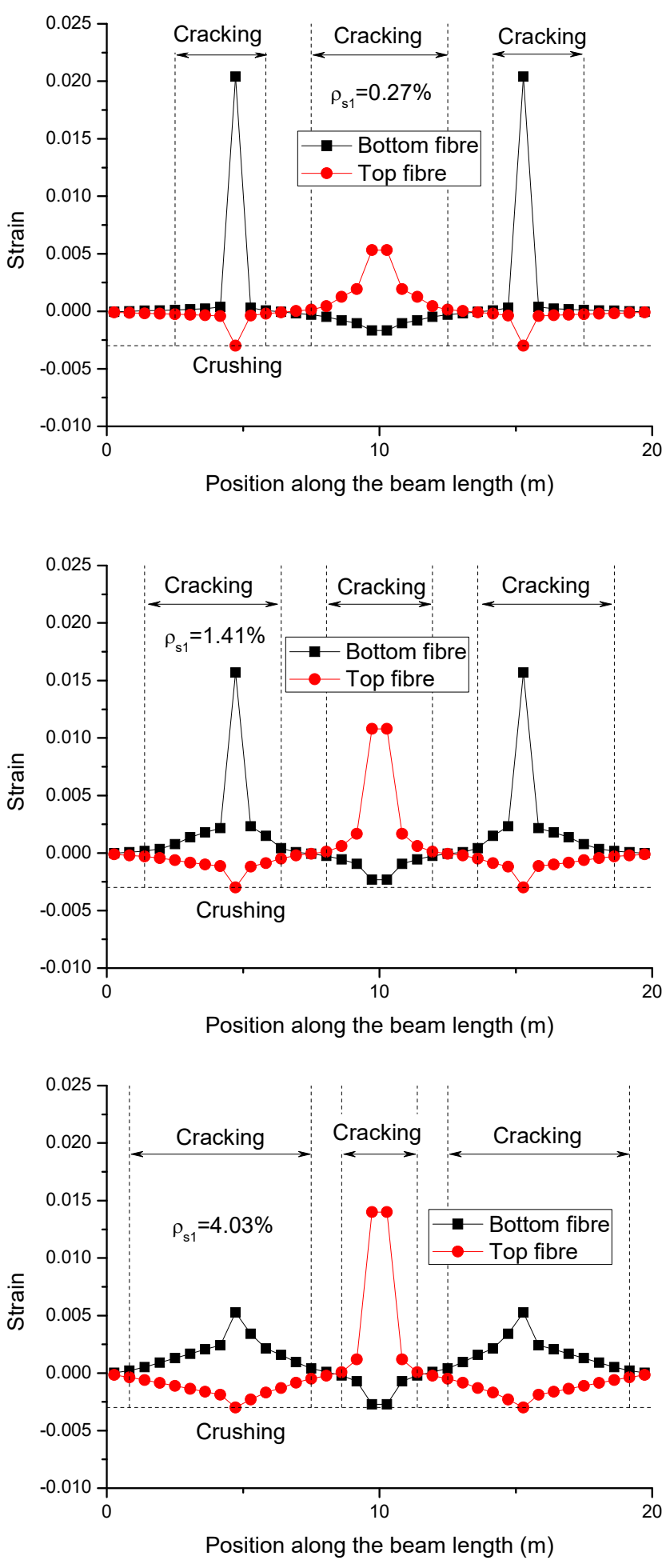

Fig. 5. Strain distribution at ultimate at the bottom and top fibres of the beams with different $\rho_{s 1}$ values. 


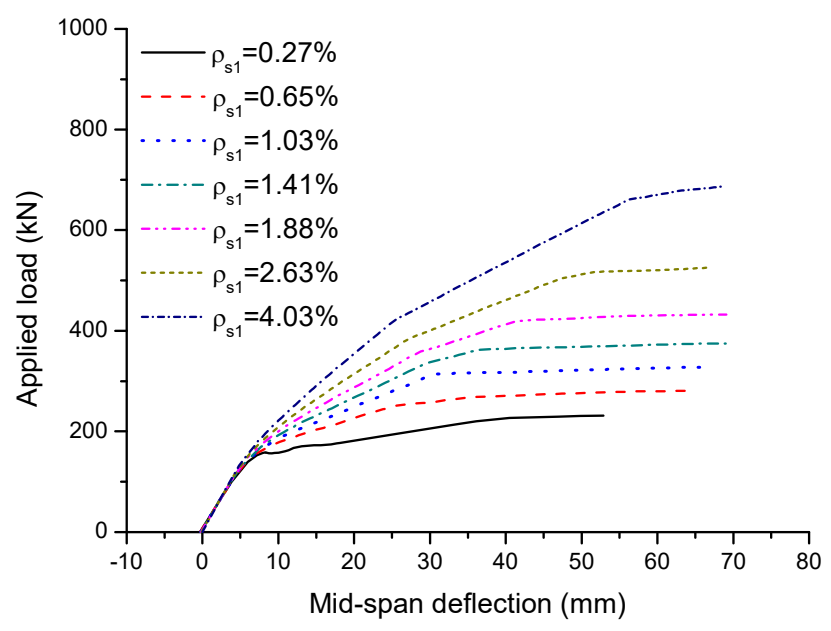

Fig. 6. Load-deflection curves for different $\rho_{s 1}$ values. 


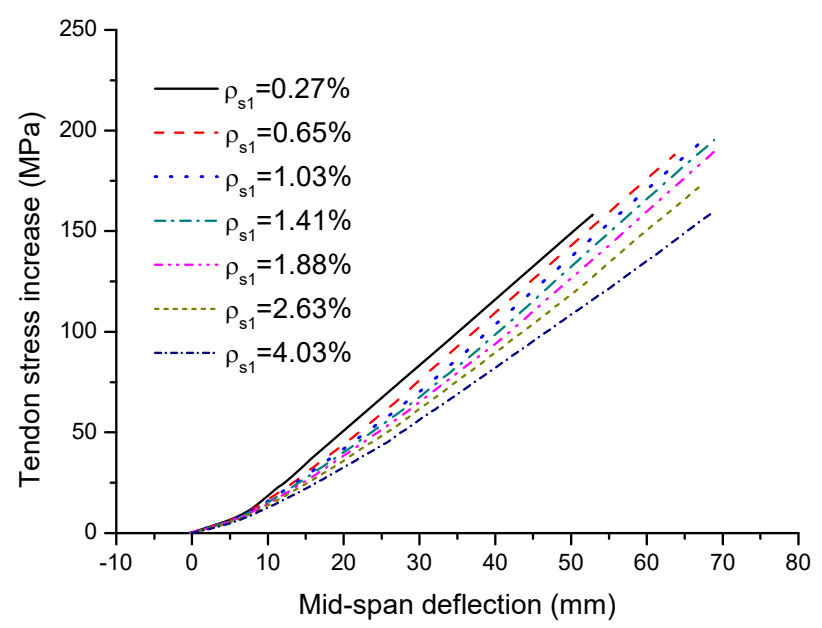

Fig. 7. Deflection development with the tendon stress increase for different $\rho_{s 1}$ values. 


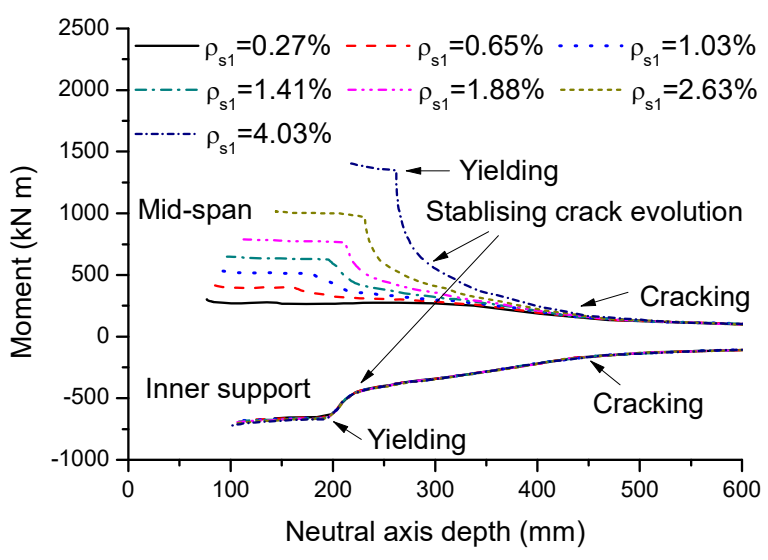

Fig. 8. Neutral axis evolution with the moment for different $\rho_{s 1}$ values. 

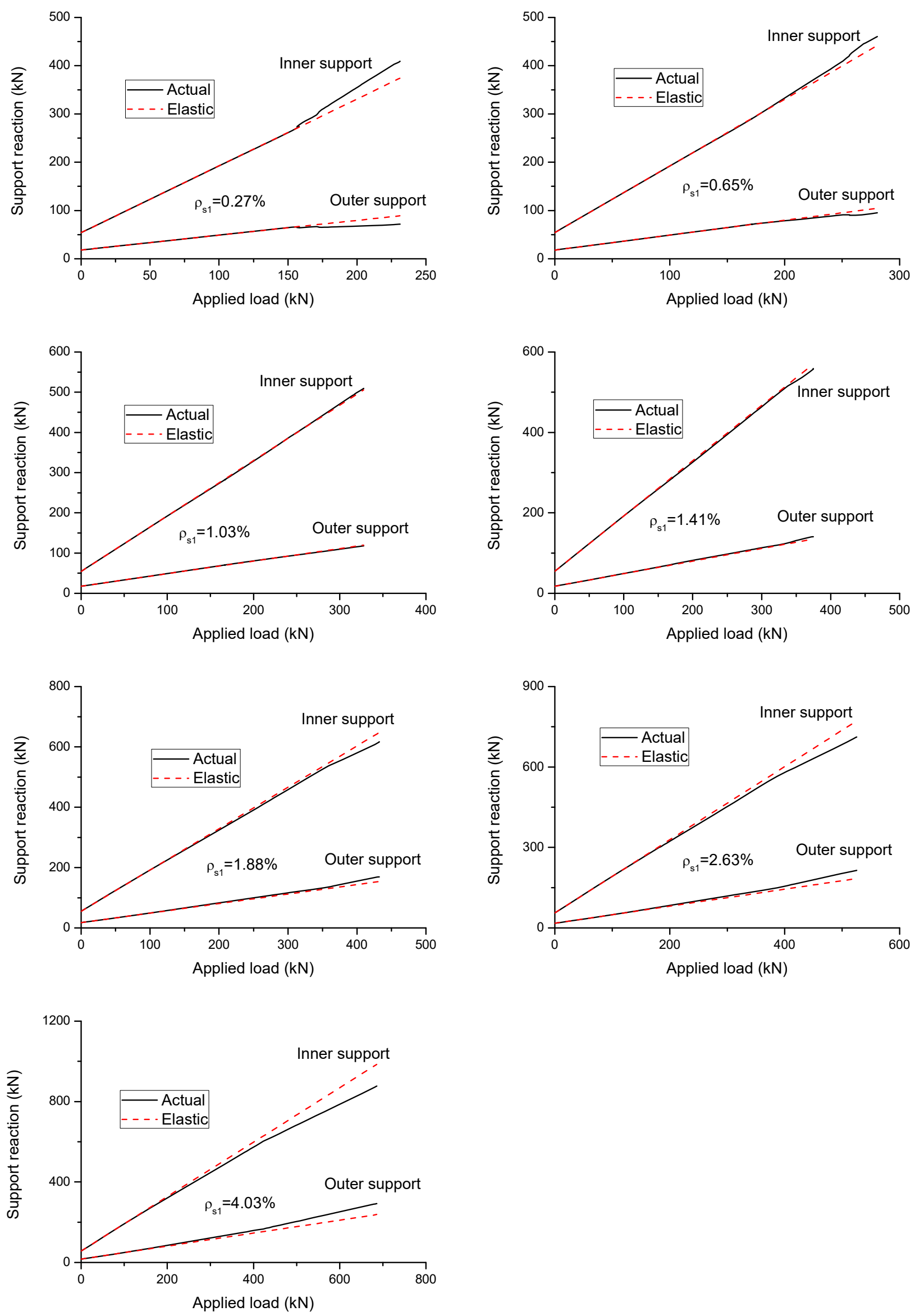

Fig. 9. Load-reaction curves for different $\rho_{s 1}$ values. 

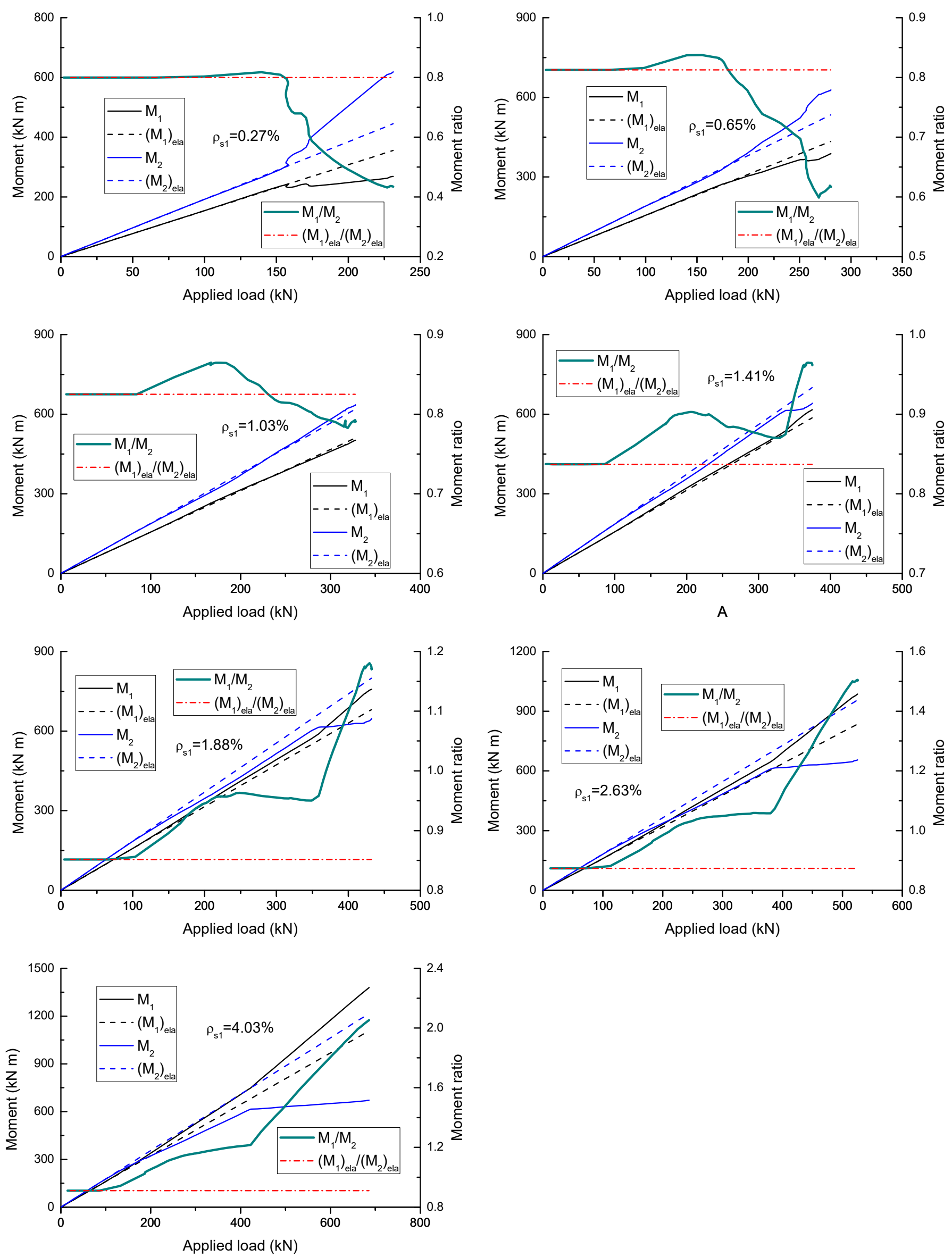

Fig. 10. Evolution of moments and moment ratio for different $\rho_{s 1}$ values. 

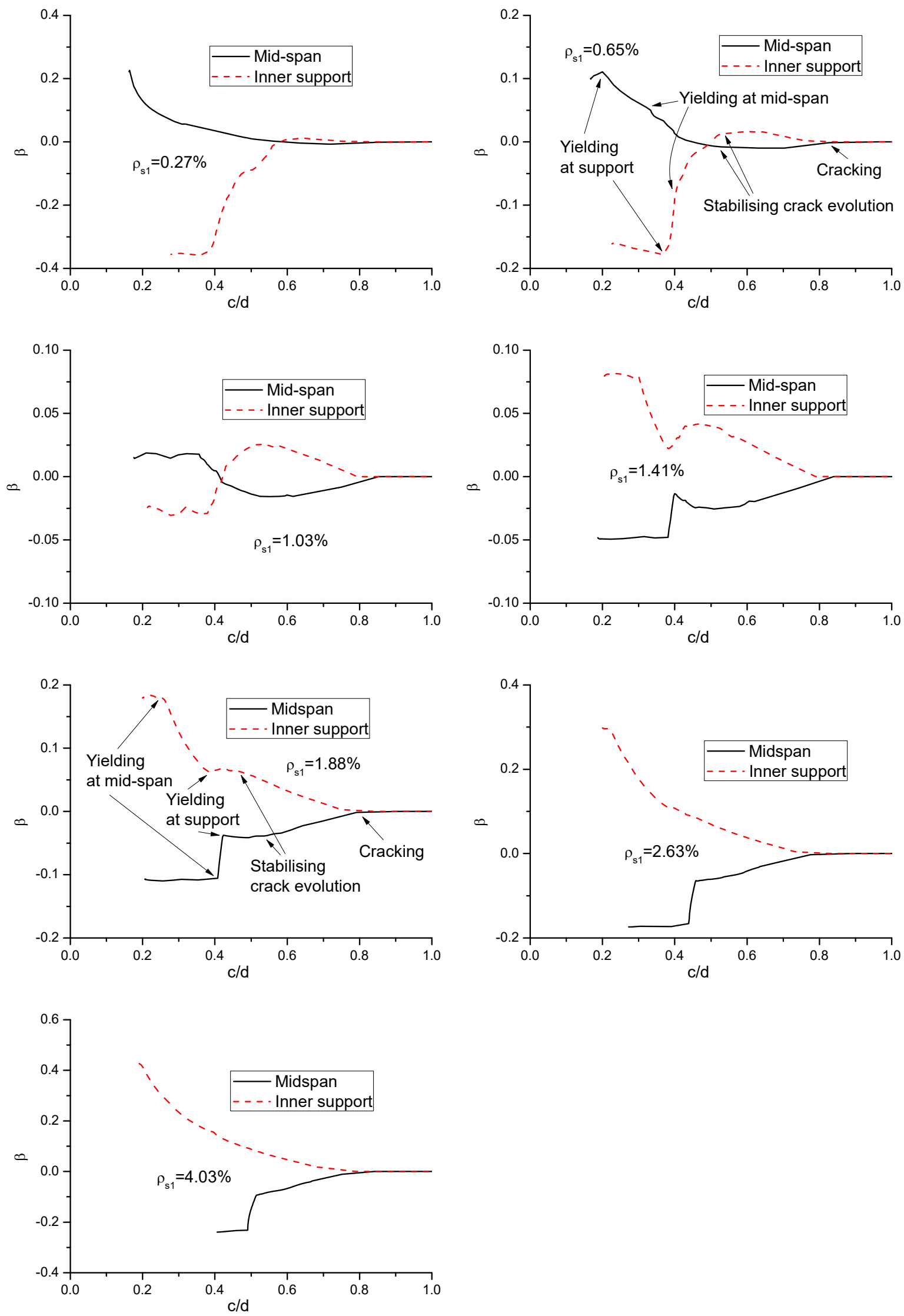

Fig. 11. Neutral axis evolution against moment redistribution for different $\rho_{s 1}$ values. 


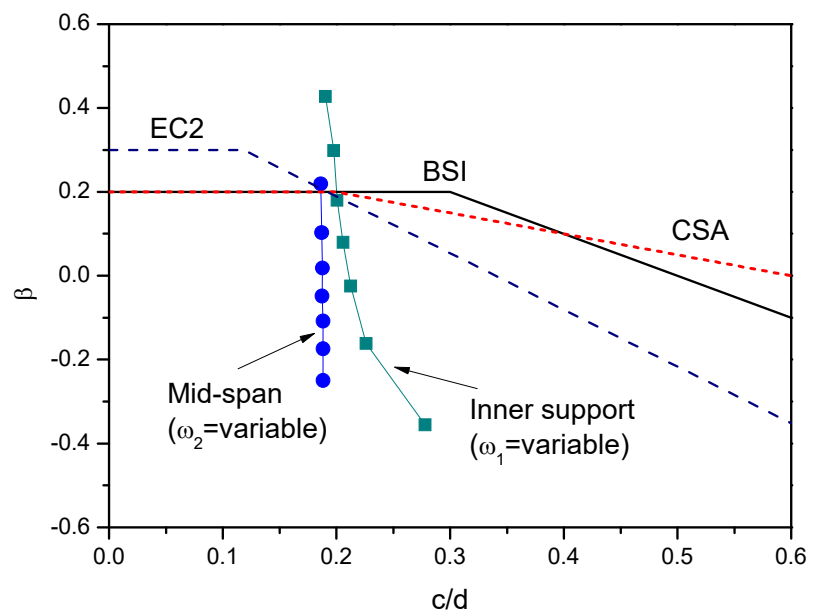

Fig. 12. The $\beta$-c/d curves by FEA and different codes. 

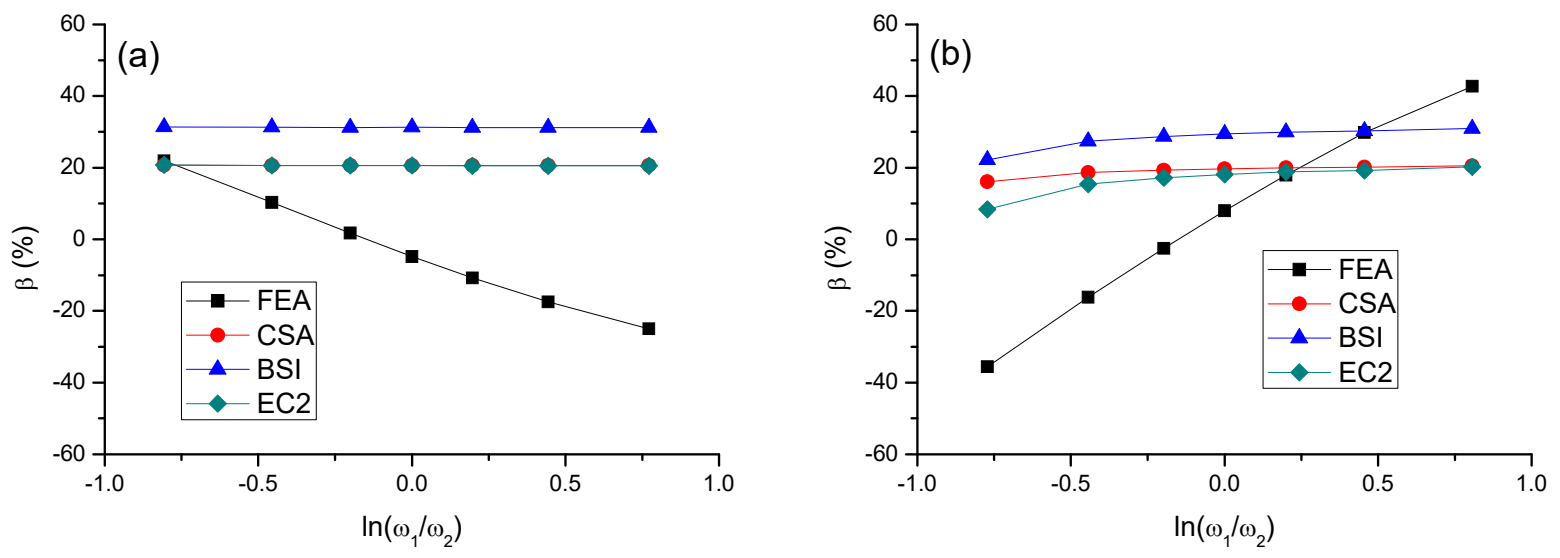

Fig. 13. The $\beta$ - $\ln \left(\omega_{1} / \omega_{2}\right)$ relationships according to FEA and different codes. (a) mid-span ( $\omega_{2}=$ variable $)$; (b) inner support $\left(\omega_{1}=\right.$ variable $)$. 

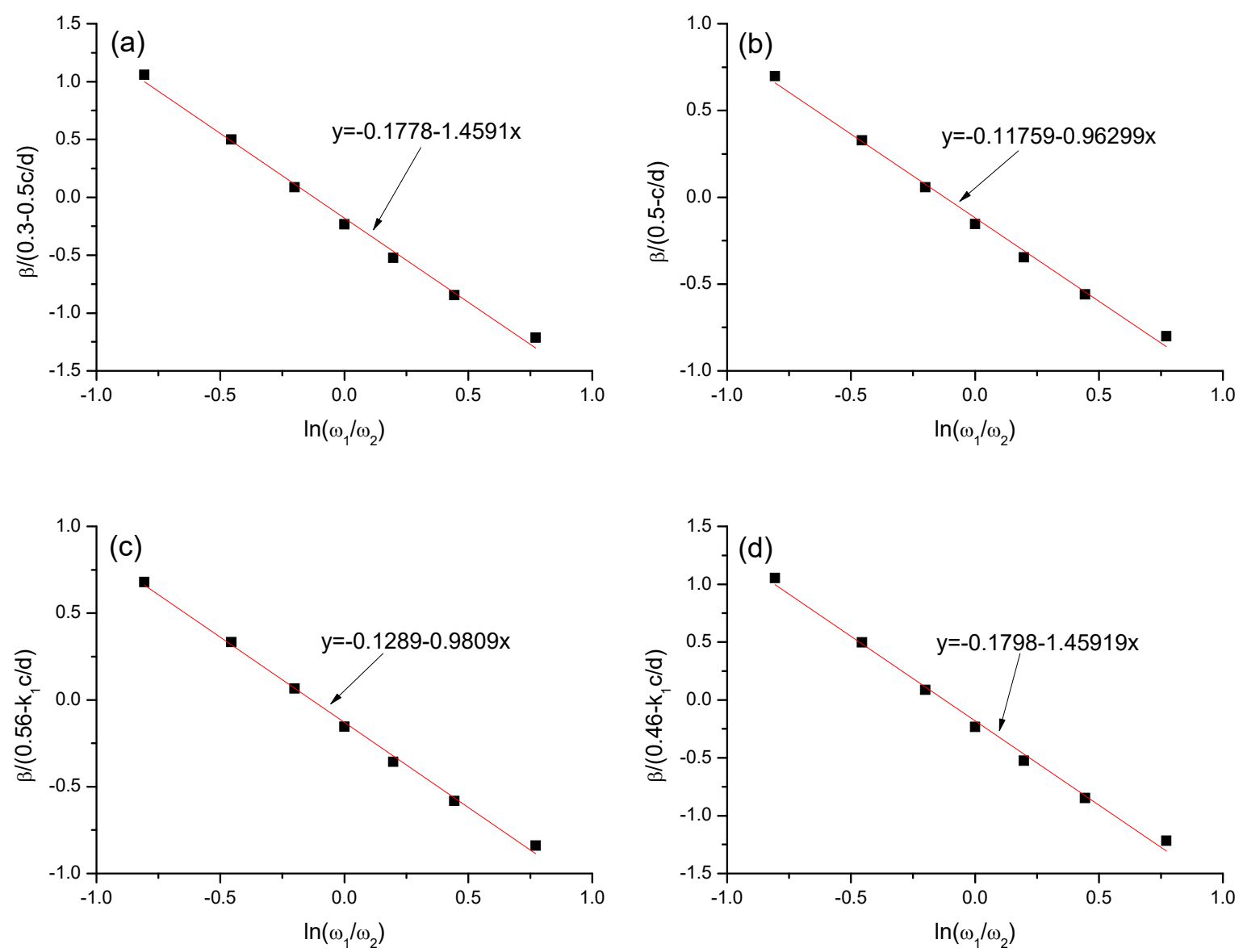

Fig. 14. Fit curves for the mid-span section. (a) $\lambda_{c s a}$; (b) $\lambda_{b s i}$; (c) $\lambda_{e c 2}$ for $f_{c k}=40 \mathrm{MPa}$; (d) $\lambda_{e c 2}$ for $f_{c k}=60 \mathrm{MPa}$. 

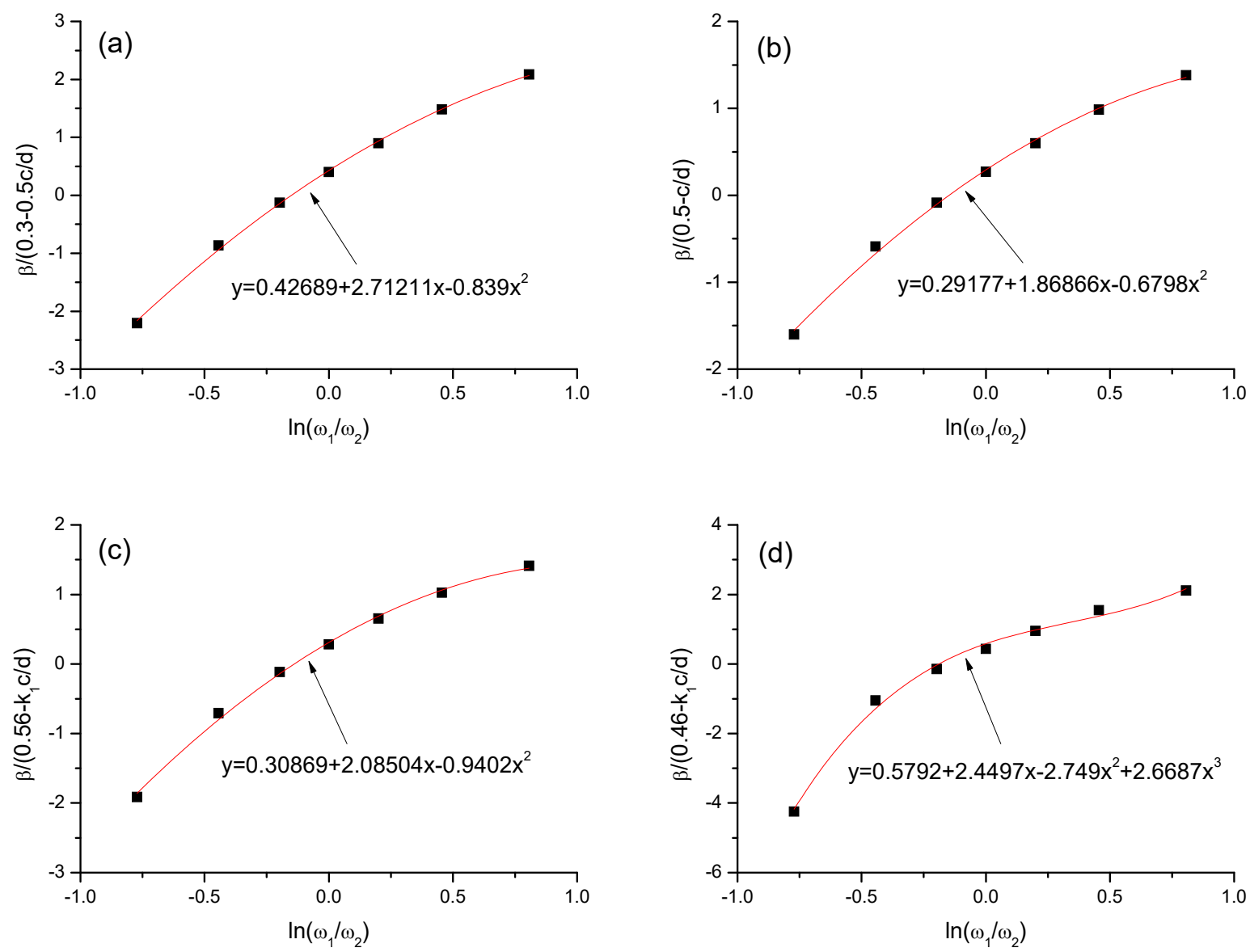

Fig. 15. Fit curves for the inner support section. (a) $\lambda_{c s a}$; (b) $\lambda_{b s i}$; (c) $\lambda_{e c 2}$ for $f_{c k}=40$ $\mathrm{MPa} ;(\mathrm{d}) \lambda_{e c 2}$ for $f_{c k}=60 \mathrm{MPa}$. 

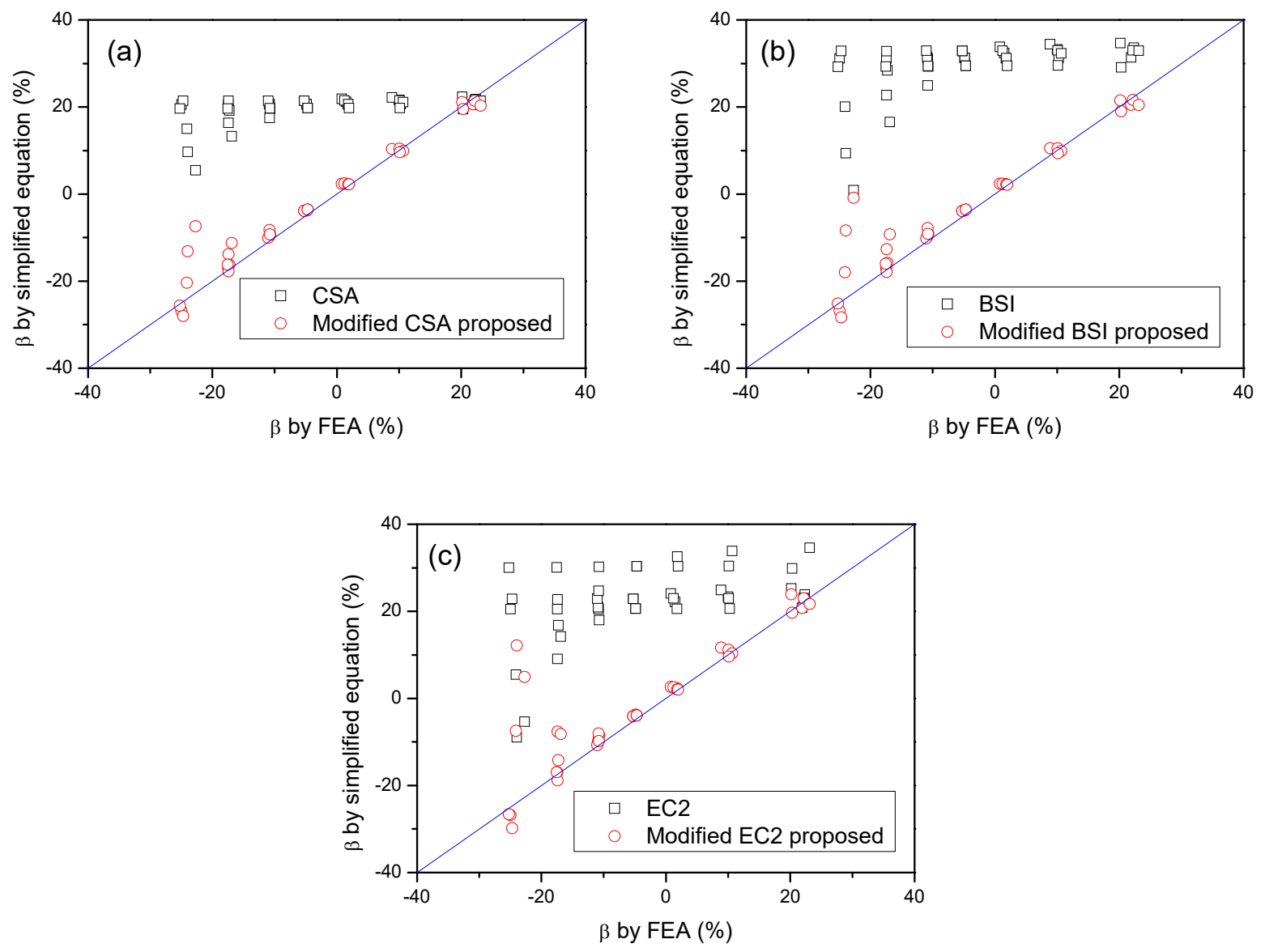

Fig. 16. Correlation of simplified equations for the mid-span section with $\beta$ by FEA. (a) CSA and modified CSA equations; (b) BSI and modified BSI equations; (c) EC2 and modified EC2 equations. 

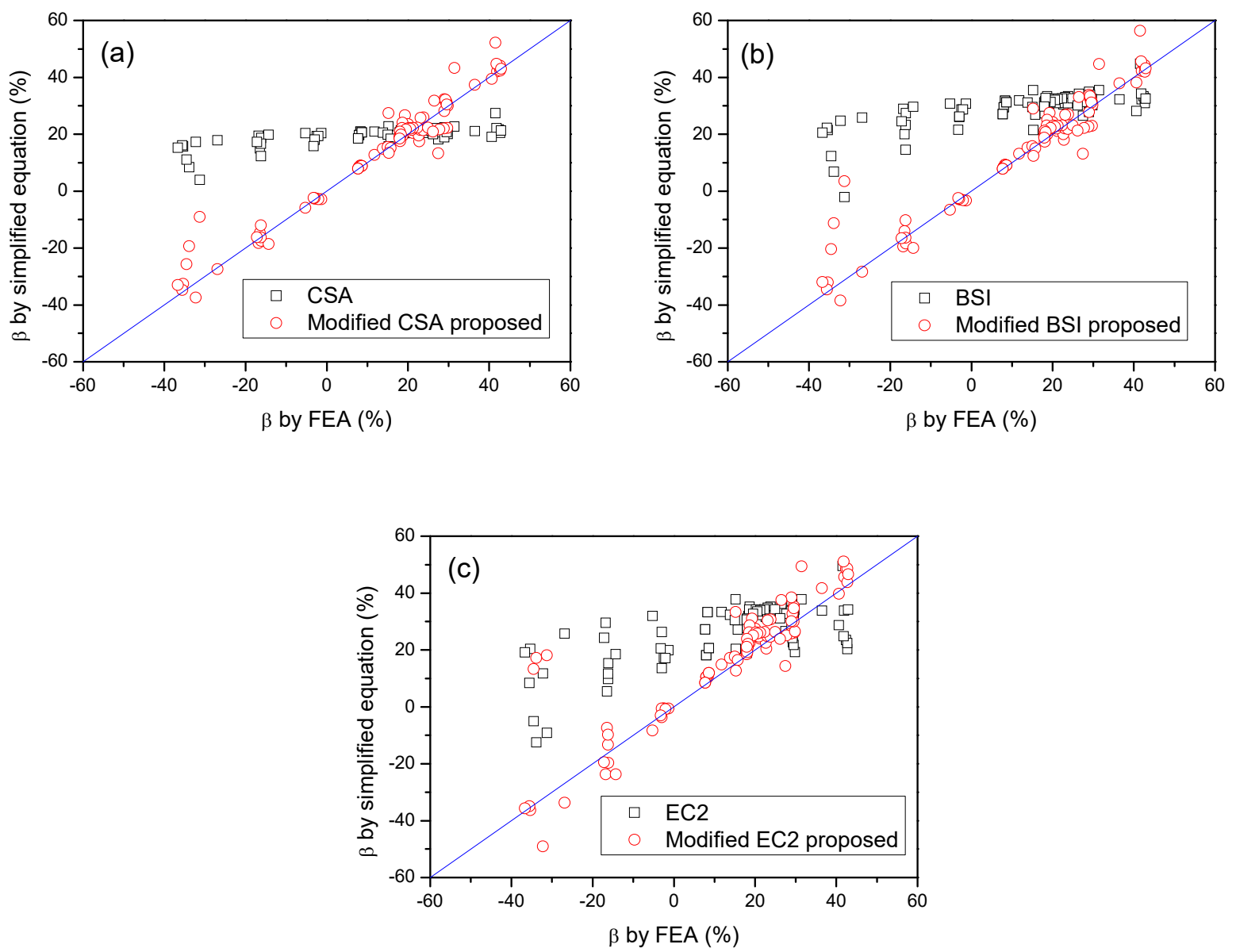

Fig. 17. Correlation of simplified equations for the inner support section with $\beta$ by FEA. (a) CSA and modified CSA equations; (b) BSI and modified BSI equations; (c) EC2 and modified EC2 equations. 